\title{
Migration and Entrapment of DNAPLs in Heterogeneous Systems: Impact of Waste and Porous Medium Composition
}

The Offices of Energy Research and Environmental Management

U.S. Department of Energy

Grant \# FG07-96ER14702

Annual Report

June 2004

Project Director:

Linda M. Abriola

Co-Principal Investigator:

Avery H. Demond

Department of Civil and Environmental Engineering

The University of Michigan

Ann Arbor, MI 48109-2125 


\section{Research Objective}

Previously funded EMSP research efforts were directed towards the quantification of dense nonaqueous phase liquid (DNAPL) migration and entrapment behavior in physically and chemically heterogeneous systems. This research demonstrated that chemical heterogeneities can have a significant influence on DNAPL fate and persistence. Previous work, however, was limited to examination of the behavior of pure DNAPLs in systems with simple and well-defined aqueous and solid surface chemistry. The subsurface chemical environments at many DOE sites, however, are generally more complex than these idealized systems, due to the release of complex mixtures of wastes and more complex physical and chemical heterogeneity. The research undertaken in this project seeks to build upon our previous research experience and expertise to explore the influence of waste and porous media composition on DNAPL migration and entrapment in the saturated zone. DNAPL mixtures and soils typical of those found across the DOE complex are being used in these studies. Many of the experimental procedures and protocols used herein are based upon those developed under previous EMSP funding. This past work also provides the conceptual framework for characterizing and interpreting experimental results, mathematical model development, and inverse modeling protocols. Specific objectives of this research include:

1) Relate measured interfacial properties for representative wastes and soils to parameters such as mineralogy, organic carbon content, $\mathrm{pH}$, ionic strength, and DNAPL acid and base numbers.

2) Assess predictive procedures to estimate interfacial properties for DOE wastes and soils.

3) Deduce mechanisms of interfacial property alteration.

4) Quantify the influence of waste and porous medium composition on hydraulic properties and residual saturation.

5) Develop and assess constitutive hydraulic property and residual saturation models.

6) Explore the migration and entrapment behavior of model DNAPL wastes in spatially and temporally heterogeneous systems.

7) Development and validation a multiphase flow model to simulate the migration and entrapment of model DNAPL wastes in heterogeneous systems.

8) Investigate the up-scaling of findings from batch and soil column experiments to larger systems.

\section{Research Progress and Implications}

This section summarizes research conducted towards the accomplishment of the above objectives in the final year of this 4 year project.

As part of the research investigating the heterogeneity of wettability at waste sites, the wettability, surface composition and surface charge of six natural materials, clean silica, a geologically young agricultural soil containing humic acid (Ann Arbor II soil), two shales (Lachine and Garfield), a bituminous coal (Waynesburg), and graphite are being measured (objectives 1,2 and 3). Previous findings suggested that the presence of organic carbon on the surface of a material alone is not sufficient to cause it to be wetted by a representative DNAPL (tetrachloroethylene). Contact angle measurements made at the isoelectric $\mathrm{pH}$ have shown that in the absence of sorbed surface active fluid contaminants, most surfaces at typical groundwater conditions are preferentially wet by water even if composed of nearly $100 \%$ carbon. Contact angle measurements have also demonstrated that the wettability of the natural solid surfaces depends on the order of fluid contact to the extent that Lachine, Garfield, Waynesburg, and 
graphite are wet by water when equilibrated in water and water is the receding fluid. On the other hand these surfaces are wet by tetrachloroethylene when equilibrated in tetrachloroethylene and tetrachloroethylene is the receding fluid. Quartz, however, remains water-wet regardless of equilibration time or drop configuration. Continued analysis with FT-IR has shown that materials with carboxylic acid or other oxygen containing functional groups do not appear to be organic-wet even if contacted by the organic in a dry state. However, saturated or unsaturated alkanous chains, and methyl groups are associated with the hard carbon surfaces (Lachine Shale, Garfield Shale, Waynesburg Coal, and Graphite) that are less strongly water-wetting.

Work in a previous funding period examined the individual impact of organic acids and organic bases on interfacial tension and wettability. In this funding period the behavior of a mixed waste consisting of a DNAPL containing both an organic acid and base was examined (objectives 1, 2 and 3). Results from this work suggest that the interfacial activity of waste mixtures cannot be predicted from the superposition of activities measured for individual waste components; in fact, the presence of a component that individually has no effect may enhance the impact of another component. The analysis of the distributions of both the organic acid and the organic base as a function of $\mathrm{pH}$ suggested that a new surface-active species may form in the mixed waste. The speciation simulation showed that this newly formed species may account for the synergistic phenomenon of interfacial behaviors seen in the mixed waste containing an organic acid and an organic base. The observed substantial increases in the contact angle and decreases in interfacial tension will significantly alter DNAPL migration and entrapment in the subsurface as demonstrated in the numerical simulations produced as another part of this project (objectives 6 , 7 and 8).

A series of capillary pressure/saturation experiments and multistep column outflow experiments was conducted to estimate capillary retention and relative permeability functions for DNAPL in media with various wetting properties (objectives 4 and 5). Capillary pressure/saturation data, generated in small pressure cell experiments, facilitate independent verification of the retention functions fit to the multistep outflow experiments. A new capillary pressure/saturation predictive relationship has been developed to predict primary drainage and primary imbibition curves for soils of differing wettability. This model has been validated using data generated in the small pressure cell experiments. Results from the outflow experiments indicate that traditional capillary-based predictive models fail to capture observed relative permeability behavior at endpoint saturations. In addition, simulation results based upon traditional multiphase flow equations, failed to adequately fit observed multistep outflow rates. Discrepancies between observed and simulated outflow rates were attributed to dynamic capillary pressure effects.

Numerical investigations were undertaken to examine the potential influence of coupled textural and chemical heterogeneity on predictions of DNAPL migration and entrapment at the field scale (objectives 6, 7 and 8). Simulations suggest that the coupled influence of textural and chemical heterogeneity can have an observable effect on the distribution of organic liquids at larger scales. Incorporation of just a small amount of organic-wet solids tends to increase maximum entrapped organic saturations and reduce depths of organic penetration and the degree of vertical spreading. Results also suggest that the presence of organic-wet solids may potentially mask the effects of 
textural heterogeneity variations. Additional numerical simulations were performed to investigate the efficiency of pump-and-treat mass recovery from contaminated aquifers possessing coupled spatial variations in textural and chemical properties. Simulations indicate that mass removal behavior (i.e., the temporal evolution in aqueous phase contaminant concentration and flux) can be directly linked to DNAPL saturation architecture. Solid phase wettability was found to affect removal behavior by controlling the accessibility of the aqueous phase to the entrapped DNAPL; the impact of wettability on the kinetics of DNAPL dissolution was determined to be a secondary effect. Further, this suite of numerical simulations indicated that mass recovery behavior is highly realization specific. In contrast to flow and entrapment behavior, it is not possible to correlate mass recovery metrics to the global geostatistical parameters.

\section{Planned Activities}

In the final two months of the project experimental research efforts will continue to focus on the effect of natural soil minerals and DNAPL waste constituents on interfacial properties (objective 1, 2 and 3). Surface excess simulations of both the organic acid and the organic base will be used to examine other possible mechanisms for the synergistic phenomenon observed in the mixed waste systems (objective 3).

Data from multistep outflow experiments will be used to assess the magnitude of and the mechanisms leading to dynamic capillary pressure effects in variously wetted synthetic (uniform and fractional wettability) porous media systems (objectives 4 and 5).

\section{Information Access}

\section{$\underline{\text { Publications }}$}

Abriola, L.M., A.H. Demond, D.M. O'Carroll, H. Hsu, T.J. Phelan, C.A. Polityka and J.L. Ryder, 2004. Compositional effects on interfacial properties in contaminated systems: Implications for organic liquid migration and recovery, American Chemical Society Monograph Series (submitted).

O'Carroll, D.M., L.M. Abriola, C.A. Polityka, S.A. Bradford and A.H. Demond, 2004. Prediction of twophase capillary pressure-saturation relationships in fractional wettability systems. Journal of Contaminant Hydrology (submitted).

O'Carroll, D.M. 2004. Influence of Wettability on Dense Nonaqueous Phase Liquid (DNAPL) Constitutive Relationships in Saturated Porous Media. Ph.D. Dissertation. Department of Civil and Environmental Engineering, University of Michigan, Ann Arbor, MI.

O'Carroll, D.M., S.A. Bradford, and L.M. Abriola, 2004. Infiltration of tetrachloroethylene in a system containing spatial wettability variations. Journal of Contaminant Hydrology (in press).

Phelan, T.J., 2004. Subsurface Compositional Simulation Incorporating Solute-Chemistry Dependent Interfacial Properties. Ph.D. Dissertation. Department of Civil and Environmental Engineering, University of Michigan, Ann Arbor, MI.

Phelan, T.J., L.D. Lemke, S.A. Bradford, D.M. O'Carroll and L.M. Abriola, 2004. Influence of textural and wettability variations on predictions of DNAPL persistence and plume development in saturated porous media. Advances in Water Resources, 27(4), 411-427.

Bradford, S.A., K.M. Rathfelder, J.R. Lang and L.M. Abriola, 2003. Entrapment and Dissolution of DNAPLs in Heterogeneous Porous Media. Journal of Contaminant Hydrology, 67:133-157.

Abriola, L. M., D. M. O'Carroll, S. A. Bradford and T. J. Phelan, 2002, Compositional effects on interfacial properties in contaminated systems: implications for organic liquid migration and 
recovery, . In: Computational Methods in Water Resources, Vol 1, Proc of the XIV Intl Conf, June 23-28, Delft, The Netherlands, Developments in Water Science 47, S. M. Hassanizadeh, R. J. Schotting, W. G. Gray and G. F. Pinder, Eds., Elsevier Science, 795-802.

Bradford, S.A. and L.M. Abriola, 2001. Dissolution of residual tetrachloroethylene in fractional wettability porous media: Incorporation of interfacial area estimates. Water Resources Research, 37(5): 11831195.

Lord, D.L., Demond, A.H. and Hayes, K.F., 2000. Effects of organic base chemistry on interfacial tension, wettability, and capillary pressure in multiphase subsurface waste systems. Transport in Porous Media, 38(1-2): 79-92.

Bradford, S. A., L. M. Abriola, and F. J. Leij. 1999. Multi-fluid hydraulic properties for fractional wettability porous media. In: Characterization and Measurement of the Hydraulic Properties for Unsaturated Porous Media, Eds., M.Th. van Genuchten, F.J. Leij and L. Wu, University of California, Riverside, pp. 165-178.

Demond, A.H., K.F. Hayes, D.L. Lord, F. Desai and A. Salehzadeh. 1999. Impact of organic compound chemistry on capillary pressure relationships of sands. In: Characterization and Measurement of the Hydraulic Properties for Unsaturated Porous Media, Eds., M.Th. van Genuchten, F.J. Leij and L. Wu University of California, Riverside.

Lord, D.L. 1999. Influence of organic acid and base solution chemistry on interfacial and transport properties of mixed wastes in the subsurface. Ph.D. Dissertation. Department of Civil and Environmental Engineering, University of Michigan, Ann Arbor, MI.

\section{Presentations}

O'Carroll, D.M., T.J. Phelan and L.M. Abriola, 2004. Dynamic Capillary Pressure Effects In Multistep Outflow Experiments. Gordon Research Conference: Flow and Transport in Permeable Media, July 11-16. Oxford, England

O'Carroll, D.M., L.M. Abriola, C.A. Polityka, S.A. Bradford and A.H. Demond, 2004. Prediction of twophase capillary pressure-saturation relationships in fractional wettability systems, CGU-AGUSEG-EEGS Joint Assembly, May 17-21, Montreal, QC.

Phelan, T.J., Ramsburg, C.A. and L.M. Abriola, 2004. Numerical Modelling of Subsurface Remediation via Density Modified Displacement. Gordon Research Conference: Flow and Transport in Permeable Media, July 11-16. Oxford, England

Ryder, J.L. and Demond, A.H., 2004. Soil surface compositional effects on the wettability of aquifer materials, AGU-CGU-SEG-EEGS Joint Assembly, May 17-21, Montreal, QC.

Abriola, L.M., D.M. O'Carroll and T.J. Phelan, 2003. Exploring the Influence of Medium Wettability on DNAPL Migration and Retention Behavior: Bench Scale Experiments and Field Scale Implications. SIAM Conference on Mathematical and Computational Issues in the Geosciences, Austin, TX. March 17-20, 2003.

Abriola, L.M., A.H. Demond, D.M. O'Carroll, H. Hsu, T.J. Phelan, C.A. Polityka and J.L. Ryder, 2003. Compositional effects on interfacial properties in contaminated systems: Implications for organic liquid migration and recovery. $225^{\text {th }}$ American Chemical Society National Meeting, New Orleans, LA. March 23-27, 2003.

O'Carroll, D.M., C.A. Polityka, T.J. Phelan and L.M. Abriola, 2003. Influence of Wettability on Dense Nonaqueous Phase Liquid (DNAPL) Capillary Hysteresis Behavior and Relative Permeability in Saturated Porous Media. EGS-AGU-EUG Joint Assembly, Nice, France. April 6-11, 2003.

Phelan, T. J. and L. M. Abriola, 2003, Simulation of mass recovery of entrapped tetrachloroethene in coupled physically and chemically heterogeneous porous media, in EGS-AGU-EUG Joint Assembly, Nice, France. April 6-11, 2003.

Abriola, L.M., D.M. O'Carroll, S.A. Bradford and T.J. Phelan, 2002. Compositional effects on interfacial 
properties in contaminated systems: implications for organic liquid migration and recovery. XIV International Conference on Computational Methods in Water Resources, Delft, The Netherlands. June 23-28, 2002.

Hsu, H.L. and Demond, A.H. 2002. Determination of Interfacial Properties of Organic Liquid Wastes in the Subsurface. $76^{\text {th }}$ American Chemistry Society Colloid and Surface Science Symposium, Ann Arbor, Michigan. June 23-26, 2002.

Phelan, T. J. and L. M. Abriola, 2002, Simulation of Mass Recovery of Entrapped Tetrachloroethene in Coupled Physically and Chemically Heterogeneous Porous Media, Eos, Transactions, American Geophysical Union, vol. 83, no.47, Fall Meeting Supplement, Abstract H62B-0856.

O'Carroll, D.M., S.A. Bradford, and L.M. Abriola, 2001. Infiltration and redistribution of PCE in a system containing spatial wettability variations. Eos, Transactions, American Geophysical Union, vol. 82, no. 20, Suppl., H51B-10.

Hsu, H.L. and Demond, A.H. 2001. Determination of Interfacial Properties of Organic Liquid Wastes in the Subsurface. 24 ${ }^{\text {th }}$ Annual Midwest Environmental Chemistry Workshop, Minneapolis, Minnesota, Oct.5-7, 2001.

Hsu, H.L. and Demond, A.H. 2001. Determination of Interfacial Properties of Organic Liquid Wastes in the Subsurface. American Geophysical Union Fall Meeting, San Francisco, CA. Dec. 10-14, 2001.

O'Carroll, D.M., S.A. Bradford, and L.M. Abriola. 2000. Infiltration and redistribution of PCE in a system containing spatial wettability variations. 6th International Symposium on Evaluation of Reservoir Wettability and Its Effect on Oil Recovery, Socorro, NM. September 27-28, 2000.

Phelan, T.J., D.M. O'Carroll, S.A. Bradford, and L.M. Abriola. 2000. Evaluation of DNAPL transport parameters in fractionally wet porous media, Eos, Transactions, American Geophysical Union, vol.81, no.48, Suppl., H71B-07.

\section{Additional Information}

Publications generated within this reporting period are available as appendices to the hard copy report. 